\title{
Looking forward with ACI Avances en Ciencias e Ingenierías
}

\section{Eva 0.L. Lantsoght ${ }^{1,2^{*}}$}

\author{
Department of Engineering Structures, Civil Engineering and Geosciences, Delft University of \\ Technology, Delft, the Netherlands \\ Politécnico, Universidad San Francisco de Quito, Quito, Ecuador \\ * Corresponding author/ Autor para correspondencia: elantsoght@usfa.edu.ec
}

This issue marks the 13th volume of the journal ACI Avances en Ciencias e Ingenierías. In these 13 years, we have published a variety of articles from all disciplines of the exact sciences, biology, and engineering. Many articles focused on research done or applied in Ecuador, but we have also received contributions from international authors.

Not only have we widened the scope of articles and the geographical reach of $\mathrm{ACl}$ Avances en Ciencias e Ingenierías, but behind the scenes, we have been working hard to provide a better experience to all the users of the journal and its platform.

For our readers, we have worked over these years with a designer to make sure the layout of all articles is uniform and that each issue has a proper front cover design. We provide both the PDF of the complete issue and of each separate article.

Looking forward, our readers can expect a number of improvements. First of all, we are working on the redesign of the website. The new version will not only be more in line with the overall aesthetic of the journal, but it will also feature a reorganization of the information on the website. Besides these overall improvements, readers will also soon be able to access the articles from the last five years in HTML and XML formats. To more easily cite articles, we are planning to include a tool that allows for the direct download and importation of files for reference management software.

Licencia Creative Commons Atribución-NoComercial 4.0

For our authors, we have worked over these years to shorten the time an article is under review and to shorten the time between acceptance of a paper and its publication. Our average time to a first editorial decision is 43 days. Upon acceptance, we provide all authors with copyediting of their articles, as well as a professional design. Moreover, $\mathrm{ACl}$ Avances en Ciencias e Ingenierías is an open access journal that allows authors to retain copyright of their own work and that does not charge an article processing fee. We are able to offer these services and open access publication to our authors thanks to the support of Universidad San Francisco de Quito and its publishing house, USFQ Press.

Recibido/

Received:

28/06/2021

Publicado en línea / Published online: $31 / 08 / 2021$

Looking forward, our authors can expect a number of improvements. We are planning a migration of the software platform that we use for handling manuscripts. We will publish articles in PDF, HTML, and XML formats. For new authors, we are preparing a number of tutorial videos to help them navigate the submission process and other features of the website. We are also improving the visibility of the journal and are planning campaigns of dissemination of our contents through various social media platforms. 
For our reviewers, we have worked over these years to improve the review form we use, as well as the accessibility of the review interface of the website. We have worked on expanding our database of reviewers so that we can reach out to reviewers with articles that align as closely as possible with their interests and expertise. We also have paired up with Publons so that reviewers can easily get recognition for their peer review work on the Publons platform. Moreover, for those who do not use Publons, we are happy to give review certificates to reviewers upon request.

Looking forward, our reviewers can expect a number of improvements. The planned migration of the software platform will make it more stable and will improve the experience of our reviewers. We also plan to publish the names of the reviewers of the articles in Volume 13 in issue Number 2, to publicly thank our reviewers for their contributions to our journal.

Since 2018, ACl Avances en Ciencias e Ingenierías has been indexed in and evaluated by Latindex 2.0. In addition, the journal is indexed in MIAR (Information Matrix for the Analysis of Journals), DOAJ (Directory of Open Access Journals), REDIB (Red Iberoamericana de Innovación y Conocimiento Científico), and SIS (Scientific Indexing Services). All articles are archived through archive.org. We also use Crossref to improve the metadata of the articles we publish.

Looking forward, we are working towards uploading our contents through dialnet. Moreover, we have passed the first steps of indexation in AmelicA (which focuses on open knowledge and non-profit academy-owned open access publications) and Redalyc (red de revistas científicas de acceso abierto no commercial propiedad de la academia) and are working towards completing the requirements to be considered in these catalogues. As such, we can raise the open access profile of our journal and make its contents more visible and easier to find online.

Certainly, 2020 has been a difficult year for many of us, and these difficulties also meant a temporary setback for the journal. In 2020, it was difficult for authors to find the time to address comments of reviewers, to access their data on computers in offices that were not accessible anymore, to find reviewers who were able to take on this volunteer effort, and to make sure we made editorial decisions in due time. We have experienced delays on all sides, resulting in delayed publication of the issues of Volume 12. This year, we are working towards bridging this gap and fulfilling our expected times to publish the issues again, and at the same time we are working on all the improvements described in this editorial.

In these past years, as editor-in-chief of ACl Avances en Ciencias e Ingenierías, I have seen more and more interest in our journal and its open access profile. For that reason, we are working towards improving the experience of all users of this journal. I am convinced that this journal has a bright future ahead, and I welcome and am grateful for your interest as readers, your contributions as authors, and your invaluable comments as reviewers. 